\title{
A ADOLESCÊNCIA ENQUANTO FENÔMENO SOCIAL: POSSIBILIDADES E NECESSIDADES DE INVESTIGAÇÃO CIENTIFICA EM ENFERMAGEM*
}

\author{
Maria Amélia de Campos Oliveira** \\ Emiko Yoshikawa Egry***
}

RESUMO: Recortando para além dos critérios crono-biológicos, ou seja, compreendendo-a enquanto um fenômeno social, as autoras discutem a redefinição deste objeto para investigação em enfermagem. Com isso, propõem a ampliação do leque de conhecimentos sobre a saúde do adolescente a fim de subsidiar a transformação do perfil de saúde-doença desse grupo populacional.

\begin{abstract}
The social phenomena of adolescence: needs and possibilities to nursing research. The authors discuss the transcendence of the chronological criteria to approach the adolescence. They propose the approach of the phenomena through the social historical view, believing that the perspectives thus opened reinforce the needs and the possibilities of understanding the adolescence as an object to nursing intervention, which will enable the transformation of the health-illness profile of this population group.
\end{abstract}

\section{INTRODUÇÃO}

Em 1990, ano da promulgação do Estatuto da Criança, seu autor, o então senador Ronan Tito, a ele se referia como uma lei que cria um novo paradigma jurídico para as relações entre os adultos, crianças e adolescentes, ao instituir esses últimos como sujeitos de direito.

$\mathrm{Na}$ verdade, o Estatuto faz mais que recolocar tais relações de forma paradigmática. Adota como orientadora a doutrina sócio-jurídica para Proteção Integral, advogada pela Organização das Nações Unidas (ONU), que tem como pressuposto o valor prospectivo de cada ser humano em desenvolvimento, dado seu caráter de "portador da continuidade do seu povo e sua espécie", daí decorrendo a necessidade de sua proteção integral, por sua vulnerabilidade, e também a necessidade de políticas específicas e prioritárias para a proteção de seus direitos ${ }^{(3)}$. Ao fazê-lo, atualiza a discussão em torno do papel do Estado enquanto provedor de políticas públicas voltadas para as necessidades desse grupo populacional. Mas, por outro lado, ao universalizar critérios biológicos e cronológicos para a objetivação da adolescência, eliminando seu caráter histórico, encobre a realidade concreta das vivências singulares, impondo o que $\operatorname{ALVES}^{(1)}$ denominou "os efeitos deletérios do óbvio, do cotidiano, do senso comum."

Tornar visíveis as experiências individuais de ser adolescente e, antes de tudo, sê-lo a partir de um determinado lugar na estrutura social de uma sociedade concreta e historicamente determinada, lança matizes que obscurecem a aparente limpidez de uma definição natural e mais ou menos consagrada do que seja a adolescência.

\section{POR UMA REDEFINIÇÃO DA ADOLESCÊNCIA}

Enquanto objeto fenomênico, a adolescência in-

* Trabalho apresentado no Evento Internacional "Pesquisa em Enfermagem: uma questão de saúde", promovido pela Escola de Enfermagem da Universidade de São Paulo em São Paulo, outubro de 1992.

** Enfermeira. Professora assistente do Departamento de Enfermagem em Saúde Coletiva da Escola de Enfermagem da Universidade de São Paulo (USP).

*** Enfermeira. Professora Doutora em Enfermagem em Saúde Coletiva da Escola de Enfermagem da Universidade de São Paulo (USP). 
corpora o adolescente, mas com ele não se confunde. Trata-se então de ao se tentar objetivá-la procurar extrair através de um processo de indução de um conjunto de fenômenos singulares, enunciados sintéticos, aplicávéis a um grupo social, historicamente determinado. Ou seja, para que se constitua em objeto, a adolescência precisa se erigir em condição observável em uma multiplicidade de exentos singulares. Como diz AYRES (2) "há que existir entre particularidades dos adolescentes (indivíduos) aspectos que permitam estabelecer identidades que expressem uma condição de vários, de muitos deles (coletivo)", sendo que a matéria prima para esse recorte deve ser uma coleção de indivíduos ou eventos.

Os critérios cronológicos têm permitido a objetivação universal da adolescência, tornando sua manipulação empírica dentro do referencial positivista. Da mesma maneira, sua associação às transformações biológicas decorrentes do desenvolvimento pubertário têm possibilitado sua manipulação dentro do cânones das ciências naturais, transformando eventos a ela associados em fatores causais ou intervenientes, equivalentes às causas do fenômenos individuais, tão ao gosto do modelo da clínica.

Essa concepção multifatorial é, sem dúvida, profundamente agnóstica, na medida em que tudo tem a ver com tudo e que nunca se chega aos determinantes reais do fenômeno, dada a impossibilidade lógica de se conhecer todas as causas envolvidas na sua gênese. O que se obtém, quando muito, são recortes mais próximos de seu efeito. Como não se distingue a causação social do fenômeno, supõe-se que "fatores" sociais estejam atuando da mesma forma que os demais, sejam eles biológicos, físicos ou químicos ${ }^{(4)}$.

Pensar os fenômenos ligados à saúde e à doença enquanto um processo determinado socialmente, implica na necessidade de estabelecer uma estrutura de determinações com diferentes tipos de causalidade, a fim de visualizar como os diferentes processos se combinam para conformar o nexo bio-psíquico de um indivíduo em um dado momento ${ }^{(7)}$.

Para fazê-lo, é preciso operar modelos com conceitos analíticos tais que tenham um potencial explicativo diferenciado em relação ao objeto de estudo. LAURELL e NORIEGA ${ }^{(8)}$ destacam que os conceitos de reprodução social, de processo de trabalho e de classe social, tomados da teoria marxista da sociedade, se prestariam a esse fim.

\section{QUESTÕES DE SAÚdE OU QUESTÕES PARA A SAÚDE?}

Não há como evitar as armadilhas do reducionismo ou da universalização quando se intenta falar da adolescência sem que seja possível reconhecer quem é o que são indivíduos concretos a que ela faz referência. Ainda mais porque esses indivíduos concretos encontram o sentido de sua vida e sua realização na realidade social em que se constituem como sujeitos históricos, a partir das relações que estabelecem entre si. como resultado de sua ação humana, e que têm um caráter significativo frente à realidade concreta que as produziu $^{(6)}$.

Não obstante, e para uma primeira aproximação teórica dentro dos limites aqui pretendidos, propõe-se a adoção provisória do conceito abstrato de adolescência, localizando, ainda que de forma precária, os fenômenos que a caracterizam na segunda década de vida dos indivíduos. Assim procedendo, pode-se pensar a adolescência, nos seus termos mais genéricos, como o período de vida dos indivíduos onde operam transformações físicas e mentais expressivas ${ }^{(12)}$. Nas sociedades ocidentais contemporâneas, essas transformações estão associadas ao desenvolvimento de suas identidades sociais, expressando uma transição da infância à maturidade, tal como socialmente definidas.

A qualidade e a intensidade dos fenômenos que ocorrem nas esferas biológica, mental e das relações sociais irão variar segundo as características concretas das sociedades onde se desenvolvem e de acordo com a posição do adolescente e sua família e/ou micro-grupo social na estrutura societária. Tais variações irão se expressar em situações potencialmente geradoras de carecimentos ou conflitos, podendo se constituir em questões de saúde.

Para dimensioná-las, AYRES(2) propõe que sejam abordadas através dos critérios epidemiológicos. de magnitude, transcendencia e vulnerabilidade. $\mathrm{Na}$ população brasileira, a porcentagem de indivíduos adolescentes, tal como definidos pela OMS, ou seja, aqueles localizados na faixa dos 10 aos 19 anos de idade, era de $22,5 \%$ em 1980 . Para uma população total estimada em 145 milhões de habitantes em 1989, o contigente populacional dos adolescentes poderia estar próximo dos 33 milhões, o que, por si só, se constitui um indicador indireto da magnitude dos problemas que se colocam para a área da saúde ${ }^{(9)}$.

Analisando a mortalidade da população adolescente nos anos de 1977, 1980 e 1985 em nove estados 
das regiões Sul, Sudeste e Centro-Oeste, LOLIO, HASIAK e BUCHALLA ${ }^{(9)}$ constataram uma mortalidade maior para o sexo masculino, com predominância de causas externas. Dentre elas apareceram de forma expressiva os homicídios e os acidentes de trânsito e também os suicídios, traduzindo a violência social nos grandes centros urbanos. Puderam observar nesse período um declínio das mortes por doenças infecciosas e parasitárias, destacando um número importante de óbitos por doenças crônicas nao transmissíveis, como as doenças do aparelho circulatório e os neoplasmas, o que não seria de se esperar nessa faixa etária. De forma considerável apareceram também as doenças classificadas como do sistema nervoso e dos órgãos dos sentidos, representadas quase sempre por meningites e complicações de infecções dos ouvidos. Esses dados corroboram a análise feita por YUNES e PRIMO $^{(14)}$ a respeito das características da mortalidade dos adolescentes brasileiros no ano de 1980 .

Os dados acima referidos apontam para uma causação marcadamente social no perfil de mortalidade dos adolescentes, daí a inadequação das práticas assistenciais de saúde no sentido de transformá-lo, dado que se orientam predominantemente para agravos de causa biológica.

Para as adolescentes do sexo feminino, as questões de saúde ligadas à gestação, ao parto e ao puerpério são responsáveis pelos maiores coeficientes de morbi-mortalidade para as regiões mais pobres do Brasil e da América Latina, coeficientes esses que são proporcionalmente maiores para as mulheres adolescentes que para as adultas ${ }^{(11)}$.

Justificativa para isso pode ser encontrada no fato de que a gravidez, em idades precoces nos grupos sociais mais carentes, determina que os eventos ligados à gestação e ao parto se dêem em condições sanitárias bastante adversas. Também o caráter de clandestinidade de que se reveste a gravidez para grande parte das adolescentes resulta na ausência de acompanhamento pré-natal e mesmo em comportamentos sociais de risco, como a prática de abortos clandestinos.

Há que se considerar também as especificidades biológicas próprias desse grupo, que podem resultar em complicações na gravidez e no parto, como a imaturidade do sistema hormonal, o déficit de nutrientes frente às necessidades metabólicas basais aumentadas, a desproporção feto-pélvica, as distócias uterinas, entre outras. Isso sem mencionar as repercussões psicológicas e nas relações sociais resultantes de uma gravidez indesejada, frente a situações pouco estáveis do ponto de vista emocional e mesmo econômico.

No que diz respeito à transcendência dos fenômenos ligados à saúde, esta tradicionalmente considera o padrão morbidade e mortalidade dos indivíduos correlacionando-o com alterações na sua capacidade produtiva. Sob essa ótica, e quando se considera que no adolescente estão ocorrendo mudanças fundamentais no nível do corpo bio-psíquico e no das relações sociais, transformações estas que irão repercurtir sobre suas potencialidades enquanto adultos, há que se atribuir às suas questões de saúde uma transcendência significativa.

Na perspectiva da vulnerabilidade, pergunta-se até que ponto os serviços de saúde têm conseguido responder aos carecimentos específicos desse grupo populacional. AYRES (2), chega a afirmar que se tratam de práticas assistenciais tão pouco impactantes do ponto de vista social que chegam mesmo a se contrapor às finalidades que as justificam. Para ele, a adolescência é uma questão que "...intersecciona, mas não se restringe aos limites do corpo, do natural (...) expressando-se relativamente pouco em agravos organicos". Dessa forma, a objetivação dos adolescentes para as práticas de saúde se dá de uma forma bastante específica, em que o substrato biológico não deveria sera dimensão dominante a orientar a intervenção. Ainda assim, a assistência ao adolescente nos serviços de saúde, quando existe, tem se centrado nos aspectos biológicos envolvidos nos fenômenos de crescimento e desenvolvimento, utilizando instrumentos tradicionais das práticas institucionais de saúde, daí seu poder de interferência limitado sobre os perfis de morbi-mortalidade.

\section{REDEFINIR OBJETO E PRÁTICAS: UMA TAREFA PARA A ENFERMAGEM?}

Na perspectiva da redefinição do objeto adolescência, cabe perguntar se não seria necessário transformar as práticas de assistência à saúde ao adolescente para que a objetivação do seu processo de saúde/doença não se subordine a uma prática eminentemente cínica, onde o objeto de intervenção se define primordialmente no nível individual, com base na anamnese, no exame físico e nos exames complementares. Em caso afirmativo, em que medida esta tarefa se coloca para a enfermagem?

No denominado modelo de assistência individual à saúde, o trabalho da enfermagem brasileira vem se conformando historicamente enquanto um meio ou

R. Bras. Enferm. Brasilia, 46 (1): 63-67, jan./mar. 1993 
instrumento do trabalho médico. No espaço institucional de prestação de cuidar, submete-se à autoridade técnica da medicina que detém o controle do diagnóstico e institui a terapêutica ${ }^{(5)}$.

No espaço hospitalar, o trabalho da enfermagem, enquanto serviço especializado, realizado coletivamente e que não produz valor direto, se realiza através do parcelamento das tarefas entre os componentes de sua equipe. A racionalidade que orienta tal distribuição decorre de uma divisão técnica do trabalho que nem sempre opera na prática, ou seja, nem sempre as tarefas de maior complexidade, no que se refere à concepção ou à execução, são desempenhadas pelos agentes tecnicamente mais habilitados. Isso permite dizer que, no âmbito hospitalar, entre o pessoal de enfermagem opera uma divisão social do trabalho que separa os que concebem o trabalho daqueles que os executam, reservando aos primeiros - no caso, os enfemeiros - as atividades burocráticas e gerenciais ${ }^{(13)}$.

No que diz respeito à organização das práticas nas instituições prestadoras de assistência na área de Saúde Coletiva, seria apressado dizer que tais serviços adotam o modelo programático de trabalho em saúde; melhor é dizer que, em geral, adotam a racionalidade deste. Segundo NEMES ${ }^{(10)}$, a assistência médica individual se colocou como meio de realização de objetivos definidos epidemiologicamente sobre o coletivo, partindo do pressuposto que essa assistência é capaz de produzir modificações na dimensão particular dos processos de saúde/doença.

Com o propósito de aumentar a eficácia do atendimento, através do uso racional dos recursos, e visando também a extensão da cobertura, a programa- ção instituiu a consulta médica como atividade hegemônica, passando a enfermagem a executar atividades subsidiárias, como a pré e a pós-consultas médicas. Instaurou-se assim o médico como legítimo agente da programação o diagnóstico e o tratamento individuais passaram a ser usados como forma de "controle" das doenças no coletivo.

Não obstante, CASTELLANOS et al. (5) advogam que a organização tecnológica, que orienta o processo de trabalho em Saúde Coletiva, ainda permite a tentativa de recriar modelos de atuação em enfermagem com objetivos e finalidades também redefinidos para o conjunto dos agentes envolvidos em um trabalho cooperativo.

Se assim for, dado que as necessidades de saúde do adolescente se expressam relativamente pouco em agravos orgânicos, e que o fenômeno da adolescência, tal como se coloca para a saúde, é um recorte definido prioritariamente no tecido social, então a assistência à saúde a esse grupo populacional se apresenta como "locus" privilegiado para a redefinição dessas práticas.

Esta assertiva, considerada no conjunto das postulações mais gerais anteriormente enunciadas, coloca a pesquisa em enfermagem diante de um amplo leque de possibilidades investigativas acerca do fenômeno da adolescência, principalmente aquelas referentes às intervenções de enfermagem. Desta forma, possibilitará a construção de um quadro teórico de referência que assegure a unicidade entre teoria e prática, entre necessidade e possibilidade de transformação na saúde dos adolescentes.

\section{REFERÊNCIAS BIBLIOGRÁFICAS}

1. ALVES, A.C. Estado e Ideologia: aparência e realidade. São Paulo: Brasiliense, 1987. p. 11.

2. AYRES, J.R. de C. M. Adolescência e saúde coletiva: aspectos epistemológicos da abordagem programática IN:"SCHRAIBER, L. B. (org.) Programação em Saúde Hoje. São Paulo: HUCITEC, 1990. p. 139-82.

3. BRASIL, leis, etc. Lei n 8069 de 13 de julho de 1990. Dispõe sobre o Estatuto da Criança e do Adolescente e dá outras providências. IN: TITO, R. Criança e Paz. Brasília, 1990.

4. BREILH, J., GRANDA, E. Investigação da Saúde na Sociedade: guia pedagógico sobre um novo enfoque do método epidemiológico. São Paulo: Instituto da Saúde/ABRASCO, 1986.

5. CASTELLANOS, B.E.P. et al. Os desafios da enfermagem para os anos 90. IN: CONGRESSO BRASILEIRO DE ENFERMAGEM, 41 Florianópolis, 1989. Anais... Florianópolis, Associação Brasileira de Enfermagem, 1989. p. 147-69.
6. INFANTE, N. B. de, ALVAREZ, L. El processo de salud-enfermedad: un fenômeno social.Inv. Educ. Enf.. v. 4, n. 2. p. $47-54,1986$

7. LAURELL, A. C: A doença no processo social. In NUNES, E. D. Medicina Social: aspectos históricos e teóricos. São Paulo: Global, 1983. p. 1333-58.

8. A. C; NORIEGA, M. Processo de produção e saúde trabalho e desgaste operário. São Paulo: Hucitee, 1989.

9. LOLIO, C. A. DE, SANTO, A. H., BUCHALLA, C. M. Mortalidade de adolescentes no Brasil, 1977, 1980 e 1985. Rev. Saúde Públ., V. 24, n. 6, p. 481-9, 1990.

10. NEMES, M. I. B. Ação programática em saúde: recuperação histórica de uma política de programação. IN SCHRAIBER, L. B. Programação em Saúde Hoje. São Paulo: Hueitee, 1990. p. 65-116.

11. OJEDA, E. N. S. et al Adolescencia y Juventud, aspectos demográficos y epidemiológicos. In: ORGANIZACIÓN PANAMERICANA DE LA SALUD. La salud del adolescente y el joven en las Américas. Washington, 1985. (Publicación científica ${ }^{\circ} 489$ ). 
12. PFROMM NETO, S. Psicologia da Adolescência. São Paulo, Pioneira, 1975.

13. ROSA, M. T. L. da et al. O desenvolvimento técnico-científico da enfermagem: - uma aproximação com instrumentos de trabalho. CONGRESSO BRASILEIRO DE ENFERMAGEM, 41, Florianópolis, 1989. Anais... Florianópolis, Associação Brasileira de Enfermagem. 1989. p. 97-126.
14. YUNES, J., PRIMO. E. Características de la mortalidad de los adolescentes brasileños. In: ORGANIZACIÓN PANAMERICANA DE LA SALUD. La salud del adolescente y el joven en las Americas. Washington, 1985. (publicación científica ${ }^{\circ} 489$ ). 